\title{
MORINGA OLEIFERA GUM EXUDATE AS CORROSION INHIBITOR ON MILD STEEL IN ACIDIC MEDIUM
}

\author{
D. Jalajaa ${ }^{1, *}$, S. Jyothi ${ }^{1}$ ， V. R. Muruganantham ${ }^{2}$ and J. Mallika ${ }^{3}$ \\ ${ }^{1}$ Department of Science and Humanities, Chemistry Division, Kumaraguru College of \\ Technology, Coimbatore-641049, India. \\ ${ }^{2}$ Department of Mechanical Engineering, Kumaraguru College of Technology, \\ Coimbatore-641049, India. \\ ${ }^{3}$ Department of Chemistry, PSG College of Arts and Science, Coimbatore-641014, India. \\ *E-mail:.jalajaa.d.sci@kct.ac.in
}

\begin{abstract}
The present work focuses the study of corrosion inhibition efficiency of gum exudate obtained from the bark of Moringa oleifera (MO). The specimens used were mild steel coupons (MS) of specific dimensions and practical studies were carried out by using mass loss method in acidic medium. The results showed good trend in inhibition efficiency which indicated that as concentration of the inhibitor was raised percentage of inhibition efficiency too improved but declined with rise in temperature. The adsorption took place by physical adsorption of molecules on MS surface. Thermodynamic parameters were obtained and adsorption complies with Langmuir adsorption isotherm.
\end{abstract}

Keywords: Corrosion Inhibition, Gum Exudate, Mild Steel, Physical Adsorption, Thermodynamic Parameters.

(C) RASĀYAN. All rights reserved

\section{INTRODUCTION}

Corrosion is a destructive attack on metal by its reaction with the environment. It is caused by chemical and electrochemical reactions that take place due to instabilities in thermodynamic parameters of the environment. Iron and steel which are the prominent engineering materials used in industries have relatively low corrosion resistance. The biggest problem encountered with corrosion is that we do not realize it happening until some damage is already done. Besides its economic effects, corrosion is detrimental to the appearance of metals and in some cases can cause equipment/structural component failure. Use of corrosion resistant materials, applications of protective coatings or control of the environment are some of the methods for combating corrosion.

Mild steel is used in industries for various reasons and it corrodes easily and implies the need for an inhibitor. The best method to combat corrosion on mild steel in acidic medium is the use of inhibitors. Iron and steel corrosion in $\mathrm{HCl}$ medium can be controlled by organic compounds containing nitrogen, oxygen and sulphur atoms ${ }^{1-3}$. However, most of the traditional inhibitors are either synthesized or chosen from organic compounds containing heteroatoms in their molecules which are very difficult to synthesize and also expensive ${ }^{4-6}$. The investigators have started using new green corrosion inhibitors based on natural products and ecofriendly biopolymers. Low cost, high biodegradability, high availability and nontoxic nature have enabled the plant extracts to function as better inhibitors for mild steel corrosion. The scope of this work is to use Moringa oleifera gum exudate as an inhibitor for corrosion on mild steel in hydrochloric acid using weight loss method.

\section{EXPERIMENTAL}

MS coupons with the following compositions were taken:

\begin{tabular}{c|c|c|c}
\hline $\mathrm{C}$ & $\mathrm{P}$ & $\mathrm{Mn}$ & $\mathrm{Fe}$ \\
\hline $0.07 \%$ & $0.008 \%$ & $0.34 \%$ & Rest \\
\hline
\end{tabular}

Rasayan J. Chem., 12(2), 545-548(2019)

http://dx.doi.org/10.31788/RJC.2019.1224096 
The metal coupons were cut into plates of dimensions of $25 \times 10 \times 1 \mathrm{~mm}$ with a hole drilled at the top edge in order to hook the metal samples in the glass rod for immersion in the aggressive medium. $1 \mathrm{M}$ $\mathrm{HCl}$ was prepared by diluting the AR grade hydrochloric acid. The bark of $\mathrm{MO}$ tree was cut with a knife and the gum exudate was collected from the wrecked bark after few days. The collected dry gum was washed with distilled water to eliminate impurities like dust, sand and bark etc. The required amount of gum was weighed and soaked in $50 \mathrm{ml}$ of water and left for overnight. The next day after the complete dissolution of gum it was filtered. Then it was kept in a desiccator and left for few days. A transparent mass of gum sample was obtained. About $1 \mathrm{~g}$ of this purified gum was taken and dissolved in one litre of water in a standard flask. From the stock solution different concentrations of inhibitor were prepared by proper dilution.

\section{Weight Loss Measurement}

The MS sheets were abraded with sand paper from coarse to fine grade, rinsed with deionised water, and cleaned with the acetone. The cleaned coupons were weighed and kept in desiccators for further studies. The immersion experiments were performed in $100 \mathrm{ml}$ test solution by the addition of MO gum as well as for blank solution for a quantified interval of time. After a specified time of immersion the coupons were removed, washed and dried. The weights of the coupons were recorded. From the weight loss values the corrosion rates (CR) and the percentage inhibition efficiency (\%IE), were calculated by applying the equation:

$$
\begin{aligned}
& \text { Corrosion Rate }(\mathrm{mpy})=(\mathrm{KW}) /(\rho \mathrm{At}) \\
& \text { Inhibition Efficiency }=(\mathrm{W} 0-\mathrm{W}) / \mathrm{W} 0) \times 100
\end{aligned}
$$

Where, $\mathrm{W}=$ weight loss after immersion experiments in $\mathrm{mg}, \rho=$ density of the coupon in $\mathrm{mg}, \mathrm{A}=$ area of the coupons exposed in aggressive medium in $\mathrm{cm}^{2}, \mathrm{~T}=$ immersion time in hours

\section{Weight Loss Measurements}

\section{RESULTS AND DISCUSSION}

One of the important non-electrochemical techniques for the determination of CR and IE is weight loss measurement. The rate of corrosion and the inhibition efficiency on changing the concentrations of MO gum $(2,4,6,8,10 \mathrm{~g} / \mathrm{L})$ in $1 \mathrm{M}$ hydrochloric acid on mild steel were quantified for different immersion periods(1-8hrs) (Table-1). It was found that the rate of corrosion falls and the efficiency of the inhibitor arises by increasing the concentration of MO extract. The inhibition efficiency also increases and gives maximum efficiency $(80.08 \%)$ at $10 \mathrm{ppm}$ of MO gum for one hour immersion. The inhibition efficiency was also found to increase with the time of exposure. A maximum efficiency of 95.46\% was obtained for $6 \mathrm{hrs}$ immersion time with $10 \mathrm{~g} / \mathrm{L}$ of the MO. Beyond this immersion period the inhibition efficiency decreases. Thus MO gum acts as an efficient inhibitor for MS in hydrochloric acid medium up to the exposure time of $6 \mathrm{~h}$. The efficiency of the inhibitor diminishes at higher exposure period and this might be due to the biodegradation of MO on standing. ${ }^{7}$

\section{Effect of Temperature}

The effect of temperature on corrosion mitigation process was studied in hydrochloric acid medium. Temperature can alter the interaction of mild steel in acidic medium in blank solution as well as after adding MO gum. Non electrochemical technique such as weight loss experiments were performed between 303 to $333 \mathrm{~K}$ temperature ranges before and after the addition of various MO extract concentrations. The impact of MO gum concentrations on MS corrosion at elevated temperature are presented in Table-2. The rates of corrosion for all temperatures were studied. The data in the table reflects that the rates of corrosion of metal coupons were diminished on increasing the concentration of MO extract. At elevated temperature the rate of corrosion of MS lift up quickly. The shifting of equilibrium is observed at higher temperature in such a way that the desorption rate is much greater than that of the adsorption rate ${ }^{8}$. 
RASĀYAN J. Chem.

Vol. 12 | No. 2 |545 - 548| April - June | 2019

Table-1: Impact of MO Gum Concentration on MS Corrosion in $1 \mathrm{M} \mathrm{HCl}$ at Ambient Temperature

\begin{tabular}{|c|c|c|c|c|c|c|c|c|c|c|}
\hline \multirow{2}{*}{$\begin{array}{l}\text { Conc. } \\
\text { MO } \\
\text { gum } \\
\text { (g/L) }\end{array}$} & \multicolumn{2}{|c|}{$\begin{array}{c}1 \\
\text { Hour }\end{array}$} & \multicolumn{2}{|c|}{$\begin{array}{c}2 \\
\text { Hour }\end{array}$} & \multicolumn{2}{|c|}{$\begin{array}{c}4 \\
\text { Hour }\end{array}$} & \multicolumn{2}{|c|}{$\begin{array}{c}6 \\
\text { Hour }\end{array}$} & \multicolumn{2}{|r|}{$\begin{array}{c}8 \\
\text { Hour }\end{array}$} \\
\hline & $\begin{array}{c}\mathrm{CR} \\
\text { (mpy) }\end{array}$ & $\begin{array}{l}\mathrm{IE} \\
(\%)\end{array}$ & $\begin{array}{c}\mathrm{CR} \\
(\mathrm{mpy})\end{array}$ & $\begin{array}{c}\mathrm{IE} \\
(\%)\end{array}$ & $\begin{array}{c}\mathrm{CR} \\
(\mathrm{mpy})\end{array}$ & $\begin{array}{c}\mathrm{IE} \\
(\%)\end{array}$ & $\begin{array}{c}\mathrm{CR} \\
(\mathrm{mpy})\end{array}$ & $\begin{array}{l}\mathrm{IE} \\
(\%)\end{array}$ & $\begin{array}{c}\mathrm{CR} \\
(\mathrm{mpy})\end{array}$ & $\begin{array}{c}\text { IE } \\
(\%)\end{array}$ \\
\hline Blank & 0.04550 & - & 0.06020 & - & 0.04806 & - & 0.08482 & - & 0.05498 & - \\
\hline 2 & 0.01668 & 63.33 & 0.02199 & 63.46 & 0.01621 & 66.27 & 0.02066 & 75.61 & 0.03878 & 29.48 \\
\hline 4 & 0.01596 & 64.89 & 0.02000 & 66.77 & 0.01362 & 71.65 & 0.00670 & 92.10 & 0.03100 & 43.62 \\
\hline 6 & 0.01251 & 72.50 & 0.01200 & 80.06 & 0.00931 & 80.63 & 0.00518 & 93.89 & 0.02280 & 58.53 \\
\hline 8 & 0.01195 & 73.75 & 0.00749 & 87.56 & 0.00554 & 88.46 & 0.00489 & 94.24 & 0.01858 & 66.21 \\
\hline 10 & 0.00906 & 80.08 & 0.00711 & 88.35 & 0.00536 & 88.86 & 0.00386 & 95.46 & 0.01891 & 65.60 \\
\hline
\end{tabular}

The rate of corrosion in acidic medium by varying temperature can be extracted by Arrhenius equation. The energy of activation was determined from the slopes of log corrosion rate and 1/T. The data extracted from the plots are presented in Table-3. The values of energy of activation after the addition of MO gum tend to rise than those before adding the MO gum in acid solution. These obtained data are in good agreement with the reported studies ${ }^{9}$. The raise of activation energy values with MO gum indicates the adsorption mechanism follows physical nature. The calculated energy of activation for MS corrosion during the inhibition process is less than $40 \mathrm{~kJ} / \mathrm{mol}$ which corresponds to physical nature of adsorption. The negative $\Delta \mathrm{Hads}$ values indicate that the nature of adsorption is exothermic. The entropy of adsorption values diminished with MO signifying that the arrangement of additives on electrode surface in the presence of MO gum are orderly manner ${ }^{9,10}$.

Table-2: Impact of Temperature on MS Corrosion in the Presence of MO Gum in $1 \mathrm{M} \mathrm{HCl}$

\begin{tabular}{|c|c|c|c|c|c|c|c|c|}
\hline \multirow{2}{*}{$\begin{array}{c}\text { Conc. MO } \\
\text { gum } \\
(\mathrm{g} / \mathrm{L})\end{array}$} & \multicolumn{2}{|c|}{$\begin{array}{c}303 \\
\mathrm{~K}\end{array}$} & \multicolumn{2}{|c|}{$\begin{array}{c}313 \\
\mathrm{~K}\end{array}$} & \multicolumn{2}{|c|}{$\begin{array}{c}323 \\
\mathrm{~K}\end{array}$} & \multicolumn{2}{|c|}{$\begin{array}{c}333 \\
\mathrm{~K}\end{array}$} \\
\hline & $\begin{array}{c}\text { CR } \\
\text { (mpy) }\end{array}$ & $\begin{array}{r}\text { IE } \\
(\%)\end{array}$ & $\begin{array}{c}\text { CR } \\
\text { (mpy) }\end{array}$ & $\begin{array}{r}\text { IE } \\
(\%)\end{array}$ & $\begin{array}{c}\text { CR } \\
\text { (mpy) }\end{array}$ & $\begin{array}{r}\text { IE } \\
(\%)\end{array}$ & $\begin{array}{c}\text { CR } \\
\text { (mpy) }\end{array}$ & $\begin{array}{r}\text { IE } \\
(\%)\end{array}$ \\
\hline Blank & 0.03413 & - & 0.06371 & - & 0.0764 & - & 0.1987 & - \\
\hline 2 & 0.01584 & 53.53 & 0.04354 & 31.55 & 0.05272 & 30.93 & 0.1616 & 18.61 \\
\hline 4 & 0.01531 & 55.06 & 0.04094 & 35.71 & 0.04953 & 35.12 & 0.1449 & 27.04 \\
\hline 6 & 0.01402 & 58.87 & 0.03860 & 39.29 & 0.04650 & 39.11 & 0.1355 & 31.76 \\
\hline 8 & 0.01349 & 60.40 & 0.03107 & 51.19 & 0.03730 & 51.11 & 0.1311 & 33.99 \\
\hline 10 & 0.01303 & 61.74 & 0.03066 & 51.79 & 0.03724 & 51.23 & 0.1262 & 36.47 \\
\hline
\end{tabular}

Table-3: Thermodynamic Parameters of Adsorption for MS Corrosion in $1 \mathrm{M} \mathrm{HCl}$ with MO Gum

\begin{tabular}{|c|c|c|c|c|c|c|c|}
\hline \multirow{3}{*}{$\begin{array}{c}\text { Conc. } \\
\text { MO gum }(g / L)\end{array}$} & \multirow{3}{*}{$\begin{array}{c}\mathrm{E}_{\mathrm{a}} \\
\left(\mathrm{kJ} \mathrm{mol}^{-1}\right)\end{array}$} & \multirow{2}{*}{\multicolumn{4}{|c|}{$-\Delta \mathrm{G}^{\mathrm{O}}$ ads $\left(\mathrm{kJ} \mathrm{mol}^{-1}\right)$}} & \multirow{3}{*}{$\begin{array}{c}-\Delta \mathrm{H}^{\mathrm{O}} \text { ads } \\
(\mathrm{kL} \mathrm{mol}-1)\end{array}$} & \multirow{3}{*}{$\begin{array}{c}\Delta S^{\mathrm{O}} \text { ads } \\
\left(\mathrm{kI} \mathrm{mol}^{-1} \mathrm{~K}\right)\end{array}$} \\
\hline & & & & & & & \\
\hline & & $303 \mathrm{~K}$ & $313 \mathrm{~K}$ & $323 \mathrm{~K}$ & $333 \mathrm{~K}$ & & \\
\hline Blank & 45.67 & - & - & - & - & - & - \\
\hline 2 & 58.10 & 8.70 & 6.61 & 6.74 & 5.09 & 40.85 & 0.1071 \\
\hline 4 & 58.52 & 7.11 & 5.29 & 5.39 & 4.51 & 30.12 & 0.0772 \\
\hline 6 & 58.57 & 6.48 & 4.63 & 4.76 & 4.01 & 28.12 & 0.0728 \\
\hline 8 & 58.61 & 5.92 & 5.14 & 5.30 & 3.50 & 27.56 & 0.0711 \\
\hline 10 & 59.98 & 5.50 & 4.62 & 4.71 & 3.18 & 26.33 & 0.0687 \\
\hline
\end{tabular}

\section{Adsorption Isotherms}

The relationship between the base metal subjected to pickling and the inhibitor molecules can be identified by adsorption isotherm. To study the behavior adsorption and to select the more appropriate 
adsorption isotherm weight loss experiments were performed. The extent of surface coverage corresponding to various concentrations of MO gum in the temperature range of 303-333 K was used to establish the appropriate adsorption isotherm. Efforts were made to evolve various isotherms including Frumkin, Temkin, Langmuir and Freundlich. The Langmuir's isotherm (Fig.-1) established from the best fit correlation coefficient corresponds to the MO adsorption on MS. Monolayer adsorption of MO gum on the metal surface is confirmed by adsorption isotherm. ${ }^{11}$

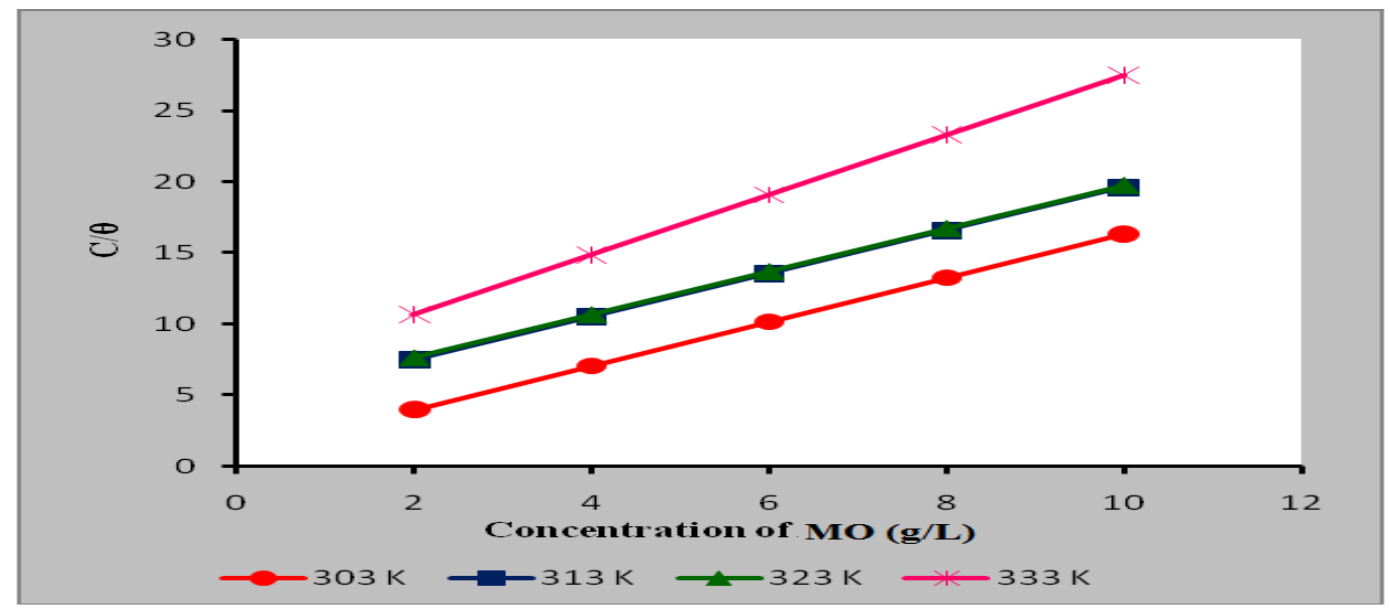

Fig.-1: Langmuir Isotherm for MS Corrosion with MO Gum in $1 \mathrm{M} \mathrm{HCl}$

\section{CONCLUSION}

Promising inhibitor for MS corrosion is extracted from Moringa oleifera gum and proved as an efficient inhibitor for acid corrosion. The efficiency of the inhibitor increased with the MO concentration but fall on raising the temperature. From the trend of inhibition efficiency with the change in temperature and from thermodynamic parameters it is evolved that the mechanism of adsorption shifts to physisorption. Langmuir adsorption isotherms are well fitted and inferred that the adsorption of MO gum on MS by monolayer protective coating.

\section{REFERENCES}

1. D. Gopi, K. M. Govindaraju and L. Kavitha, J. Appl. Electrochem., 40, 1349(2010), DOI: 10.1007/S10800-010-0092-Z.

2. X.H. Li and G.N. Mu, Appl. Surf. Sci., 252, 1254(2005), DOI: 10.1016/j.arabjc.2014.05.004.

3. X.M. Li, L.B. Tang, L. Li, G.N. Mu and G.H. Liu, Corros. Sci., 48, 308(2006), DOI: 10.1016/j.ejpc.2016.06.001

4. V. V. Torres, R.S. Amado, C.F. de Sá, T.L. Femandez, C.A. Da Silva Riehl, A.G.Torres and E. D'Elia, Corros. Sci., 53, 2385 (2011), DOI:10.20964/2018.11.38

5. S. Jyothi and K. Rathidevi, Rasayan. J. Chem., 10(4),1253(2017).

6. D. Jalajaa, S. Jyothi and J. Mallika, Rasayan .J. Chem. 10(4), 1271(2017), DOI: 10.7324/RJC.2017.1041926.

7. A.Y. El-Etre, Mater. Chem. Phys., 108, 278 (2008).

8. O. K. Abiola, J. O. E. Otaigbe and O. J. Kio, Corros. Sci., 51, 1879 (2009).

9. J. C. Da Rocha, J. A. Da Cunha Ponciano Gomes and E. D'Elia, Corros. Sci. 52, 2341(2010), DOI: $10.1016 /$ j.corsci.2010.03.033.

10. S. Jyothi and J. Ravichandran, Acta Metallergica Sinica, 27, 969 (2014), DOI: $10.1080 / 01694243.2017 .129830 /$.

11. S. Jyothi and J. Ravichandran, J. Adhes. Sci. Technol, 28, 2347(2014), DOI: 10.1080/01694243.2014.966886.

[RJC-4096/2018] 